Preprint, for presentation at the 218th ACS National Meeting to be held in New Orleans, LA, on August 22-26, 1999.

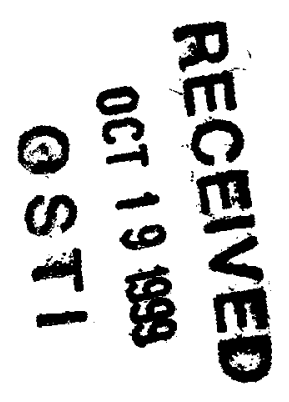

MOLECULAR SIZE AND STRUCTURE IN PYRIDINE EXTRACTS OF UPPER FREEPORT COAL AS SEPARATED BY M41S SIEVING*

J. E. Hunt, R. E. Winans, M. Ahrens, and L. Xu Chemistry Division Argonne National Laboratory Argonne, IL 60439

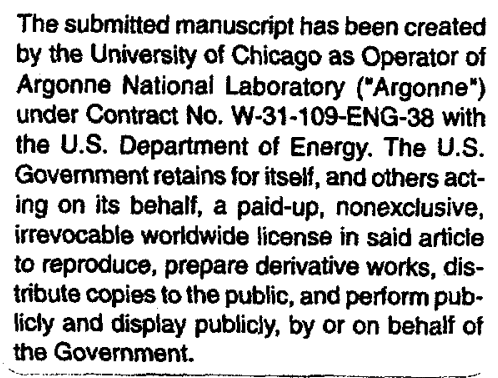

*This work was performed under the auspices of the Office of Basic Energy Sciences, Division of Chemical Sciences, U.S. Department of Energy, under contract number W-31-109-ENG-38. 


\section{DISCLAIMER}

This report was prepared as an account of work sponsored by an agency of the United States Government. Neither the United States Government nor any agency thereof, nor any of their employees, make any warranty, express or implied, or assumes any legal liability or responsibility for the accuracy, completeness, or usefuiness of any information, apparatus, product, or process disclosed, or represents that its use would not infringe privately owned rights. Reference herein to any specific commercial product, process, or service by trade name, trademark, manufacturer, or otherwise does not necessarily constitute or imply its endorsement, recommendation, or favoring by the United States Government or any agency thereof. The views and opinions of authors expressed herein do not necessarily state or reflect those of the United States Government or any agency thereof. 


\section{DISCLAIMER}

Portions of this document may be illegible in electronic image products. Images are produced from the best available original document. 


\title{
Molecular Size and Structure in Pyridine Extracts of Upper Freeport Coal as Separated by M41S Sieving
}

\author{
Jerry E. Hunt, Randall E. Winans, Mike Ahrens, and Langqiu Xu \\ Chemistry Division \\ Argonne National Laboratory \\ 9700 South Cass Ave. \\ Argonne, IL 60439
}

KEYWORDS: coal, extracts, sieving, separation, mass spectrometry

\section{INTRODUCTION}

The determination of the structure of coal has long been of interest due to its crucial importance in research on reactivity and processing. However, the chemically and physically heterogeneous nature of coals makes determination of the chemical nature of even the building blocks complicated, since the molecular structure and molecular weight distribution are not dependent on a single molecule or repeat unit as in technical polymers or biopolymers, but on a complex mixture of molecules and potential connections between them which may vary among coals.

Coal extracts have long been used to obtain coal material in solution form that can readily be characterized. However, what part of the total coal structure these extracts represent is not completely known. Pyridine has been a particularly good solvent for coal; for example, the extractability of Upper Freeport has been shown to be as high $30 \%$. Although pyridine extracts of coal have been referred to as solutions, there is good evidence that they are not truly solvated, but are dispersions which are polydisperse in particle size. ${ }^{1}$ The particle sizes may span the size range from clusters of small molecules (a few $\AA$ ) to extended clusters of large particles (a few hundred $\AA$ ), not unlike micelles, where the functional groups of molecules which interact favorably with the pyridine solvent lie at the surface of particles.

Mesoporous silicates are attractive candidates for separations due to their high surface areas and porous nature. MCM-41 is one member of a new family of highly uniform mesoporous silicate materials introduced by Mobil, whose pore size can be accurately controlled in the range $1.5 \AA-10$ $\mathrm{nm}^{2,3}$ This recently discovered M41S class of zeolites should be useful to effect size separation, due to their large pore sizes and thus their potential for the separation of larger compounds or clusters. True molecular sieving on the size range of molecular and cluster types found in coal solutions should be possible with M41S materials by tuning the pore size.

We have synthesized a mesoporous silicate material with a surface area of approximately $1100 \mathrm{~m}^{2} / \mathrm{g}$ and pore sizes of approximately $25 \AA$ and $33 \AA$. The results of a study on the ability of this mesoporous materials (M41S) to be used as stationary phases for separations of coal complexes in pyridine is the subject of this paper.

\section{EXPERIMENTAL}

The coal used in this study is the mv bituminous Upper Freeport coal (APCS 1) of the Argonne Premium Coal Samples series. ${ }^{4}$ We have used a new room temperature extractor, the Gregar extractor and traditional refluxing in pyridine to extract the coal. Approximately $10 \mathrm{~g}$ of coal was extracted in the Gregar extractor for one week. The extract was filtered and stirred with the M41S material for one week. This was then filtered and the zeolite-containing coal was extracted with methylene chloride. The extraction removed the coal material from the zeolite quantitatively.

A similar quantity of coal $(10 \mathrm{~g})$ was extracted by pyridine reflux for one week. The extract was divided and stirred for one week in $33 \AA$ and $25 \AA$ M41S material. After filtering, the zeolite material containing the coal was extracted with methylene chloride. Approximately $25 \%$ of the coal material was recovered from each zeolite by methylene chloride extraction. Further extraction with chlorobenzene resulted in only a few additional percent of coal.

Synthesis of MCM-41 was an approach combining the advantages of several literature works ${ }^{2,3,5}$. Different chain length of surfactants, ranging from dodecyltrimethylammonium to octadecyltrimethylammonium bromide, were used as template to construct a periodic mesophase. The silica source used was tetramethyl orthosilicate. The synthesis was carried out at room temperature in the 
solution of methanol and sodium hydroxide mixture. Pure silica versions of these zeolites were prepared to alleviate irreversible absorption by aluminum sites.

Mass spectra were recorded on a Kratos Maldi III instrument for laser desorption (LD) and a Kratos MS-50TA for low voltage high resolution mass spectrometry (LVHRMS). For the LD spectra, the laser intensity for the $\mathrm{N}_{2}$ laser $(337 \mathrm{~nm})$ was kept at ion appearance threshold for all samples. The LVHRMS was recorded using low energy electron ionization (18eV) to maximize ionization of high mass compounds with minimal fragmentation. TGA-DTA (thermal gravimetric analysis and differential thermal analysis) measurements were obtained on a SDT 2960 from TA Instruments. For these samples, measured against an alumina standard in a $100 \mathrm{~mL} / \mathrm{min} \mathrm{O}_{2}$ flow with a temperature ramp of $10^{\circ} \mathrm{C} / \mathrm{min}$ to $800^{\circ} \mathrm{C}$. The TGA data is also represented in its firstderivative or differential thermal gravimetry (DTG) format. Total organic loss were calculated by measuring the weight loss over the approximate temperature range of $200-600{ }^{\circ} \mathrm{C}$. XRD analyses were carried out on a Rigaku Miniflex+ instrument using $\mathrm{CuK} \alpha$ radiation, a NaI detector, a $0.05^{\circ}$ step size, and a $0.50^{\circ}, 2 / \mathrm{min}$ scan rate. XRD and SAXS showed pore sizes of $25 \AA$ and $33 \AA$ for the two M41S-class zeolites.

\section{RESULTS AND DISCUSSION}

The Gregar extractor extracted only $7.45 \%$ of the Upper Freeport coal into pyridine. The LD mass spectrum of the coal-zeolite extract showed only minimal ion intensity. The LVHRMS of this sample was used to estimate the number of aromatic rings present in the extracts. The results show that the largest mole \% of hydrocarbon containing material was zero rings $(5.5 \%)$, one ring $(2.5 \%)$, two ring $(0.8 \%)$ species. There is a small amount of material that can be attributed to multiple ring systems above three rings $(2.87 \%)$. The reason for the low extractability using this technique may be a result of room temperature pyridine extraction as opposed to refluxing pyridine for the traditional technique. Although the amount of material is less, it is interesting that the majority of this is essentially aliphatic with very little aromatic character.

The refluxing pyridine extracted $29.6 \%$ of APCS 1 , which is consistent with published results of extractabilities of this coal.

We used TGA to determine the weight loss as a function of temperature. From this data we can determine the total amount of organic material in the mesoporous zeolite. The TGA data shown in Fig 1 indicates that the $33 \AA$ pore size material contains a larger amount of coal extract from the pyridine solution than the $25 \AA$ M41S mesoporous material. This is shown as the weight loss per cent of the total sample weight of $22.6 \%$ for the $33 \AA$ material versus $15.6 \%$ for the $25 \AA$ material (Fig. $1 \& 2$ ).

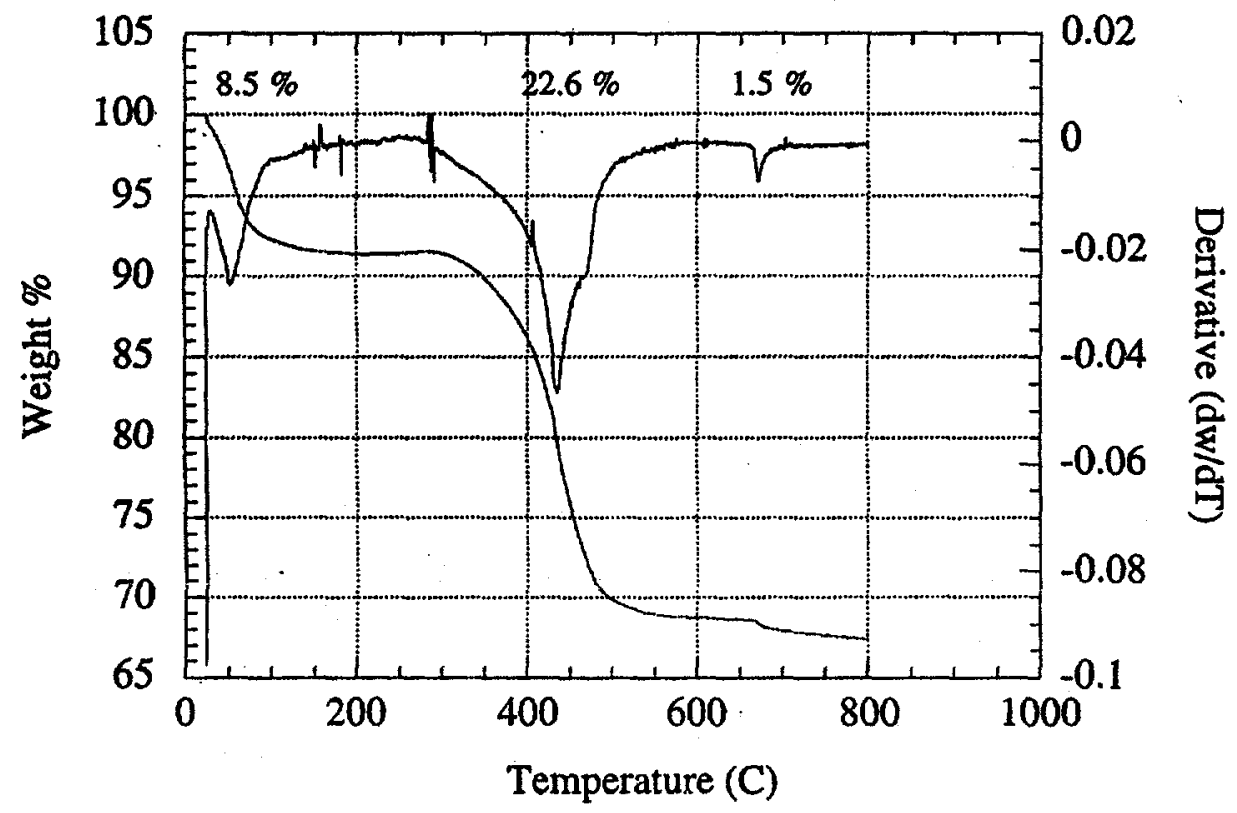

Fig. 1. The TGA of $33 \AA$ M41 S material with pyridine extract of Upper Freeport coals 


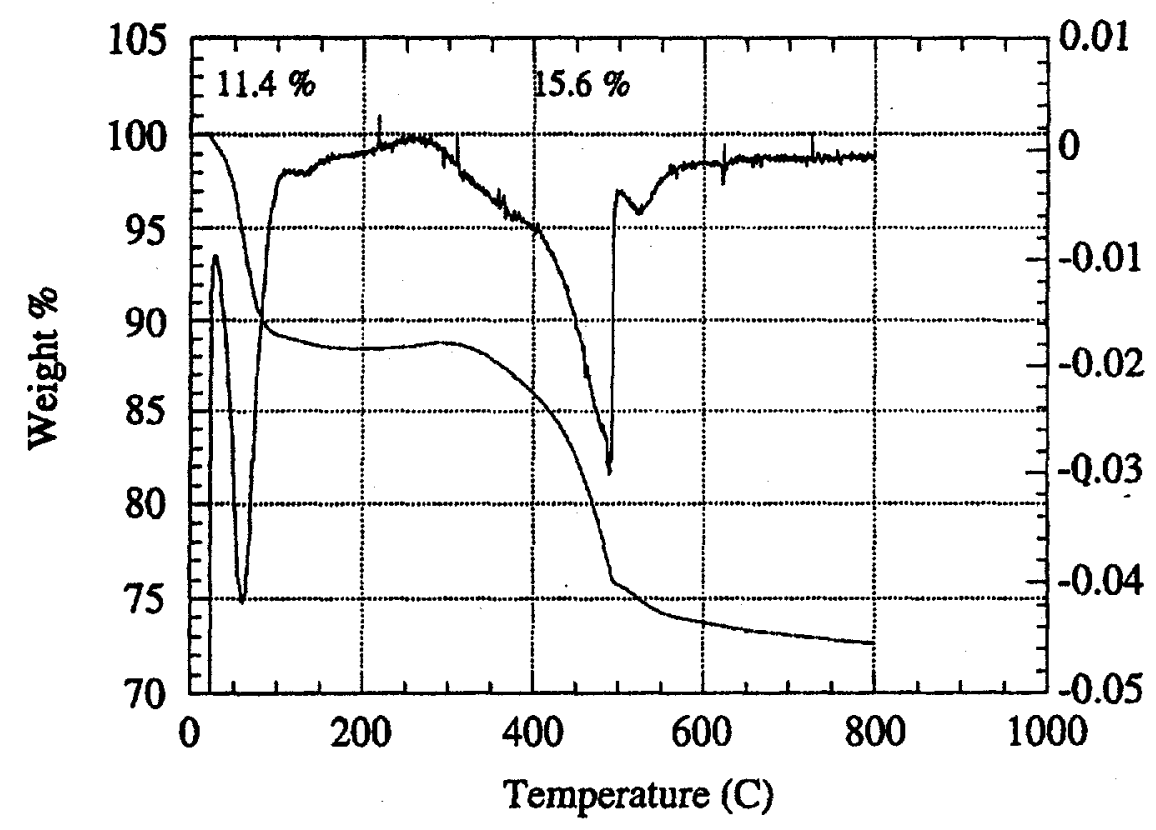

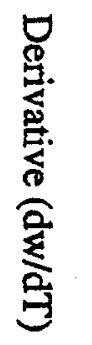

Fig. 2. The TGA of $25 \AA$ M41 S material with pyridine extract of Upper Freeport coals

Certainly, very polar material will bind to the silica. In the case of both M41S mesoporous materials only $25 \%$ can be removed from the zeolite. The more nonpolar will be extracted in the washes of coal-infused M41S material. The TGA indicates that very low molecular weight material is evolved at about $60^{\circ} \mathrm{C}$, which we assign to occluded pyridine. The major part of the organic material begins to come off at roughly $300^{\circ} \mathrm{C}$ and peaks at $440^{\circ} \mathrm{C}$ for the $33 \AA$ material and at 500 for the $25 \AA$ material. In addition, there is a distinct shoulder at 460 in the $33 \AA$ and at 520 in the $25 \AA$ which may indicate different organic compounds or clusters of compounds. The peak at 675 in the $33 \AA$ material is only $1.5 \%$ of the total weight, but may be related to very tightly bound (very polar) organic material on the silica.
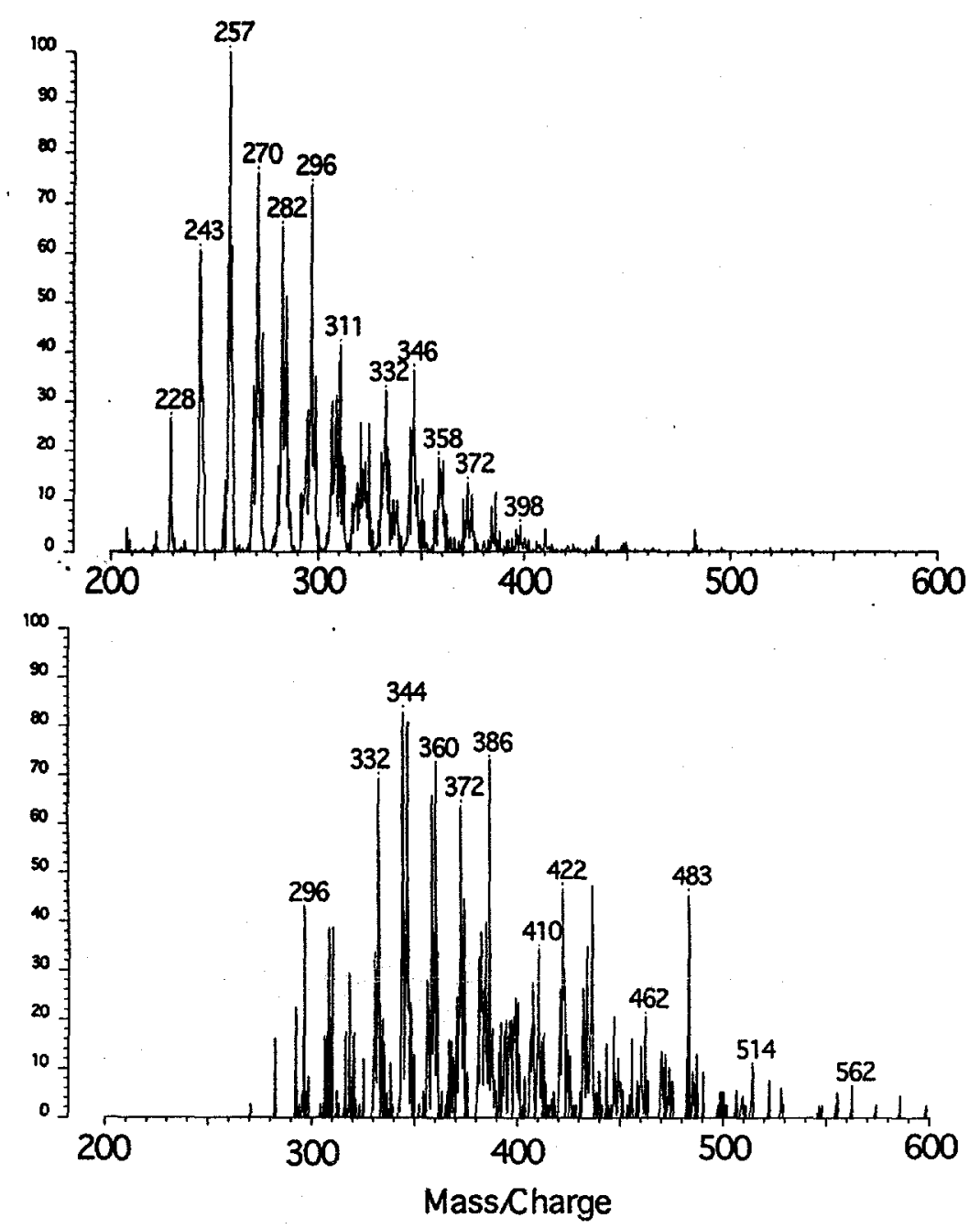

Fig. 3 The laser desorption mass spectrum of methylene chloride extract of APCS 1 imbibed M41S zeolite. $25 \AA$ pore diameter (upper panel) $33 \AA$ pore diameter (lower panel) 
The laser desorption mass spectra of the extracts from the coal-containing mesoporous zeolites is shown in figure 3 . Here there is a clear distinction in mass between the $25 \AA$ and the $33 \AA$ sieves. The average mass of the $33 \AA$ extract is higher than that of the $25 \AA$ extract by roughly 44 mass units. This would correspond to an additional ring system. Since LD chiefly accesses the aromatic content of a sample, we believe that this difference can be attributed to one additional ring in the $33 \AA$ over the 25 $\AA$ extract. That is, the separation of the extract using mesoporous sieving by M41S-class zeolites is effectively differentiating small ring sizes. This suggests that one additional ring is responsible for the separation difference between 25 and $33 \AA$. Clearly, the average molecular size of an aromatic molecule of molecular weight 300 is much smaller than either pore size. This suggests that the separation takes place on larger clusters of molecules of similar ring sizes. We suggest that molecular clusters which are manifested in the LD spectra as relatively small aromatic molecular ions are separated as large clusters of molecules. Evidence from small angle neutron scattering of pyridine coal systems shows a high polydispersity in cluster size. We may be accessing one portion of that range in the 20-30 $\AA$ size range. Further experiments with larger pore size mesoporous M41S materials are underway.

The LVHRMS results comparing the $25 \AA$ and $33 \AA$ is shown in Figure 4. The average aromatic ring size is an estimate based on the number of double bond equivalents calculated from the high resolution data. The $33 \AA$ shows an increased aromatic ring size over the $25 \AA$.

\section{Mole \% HC}

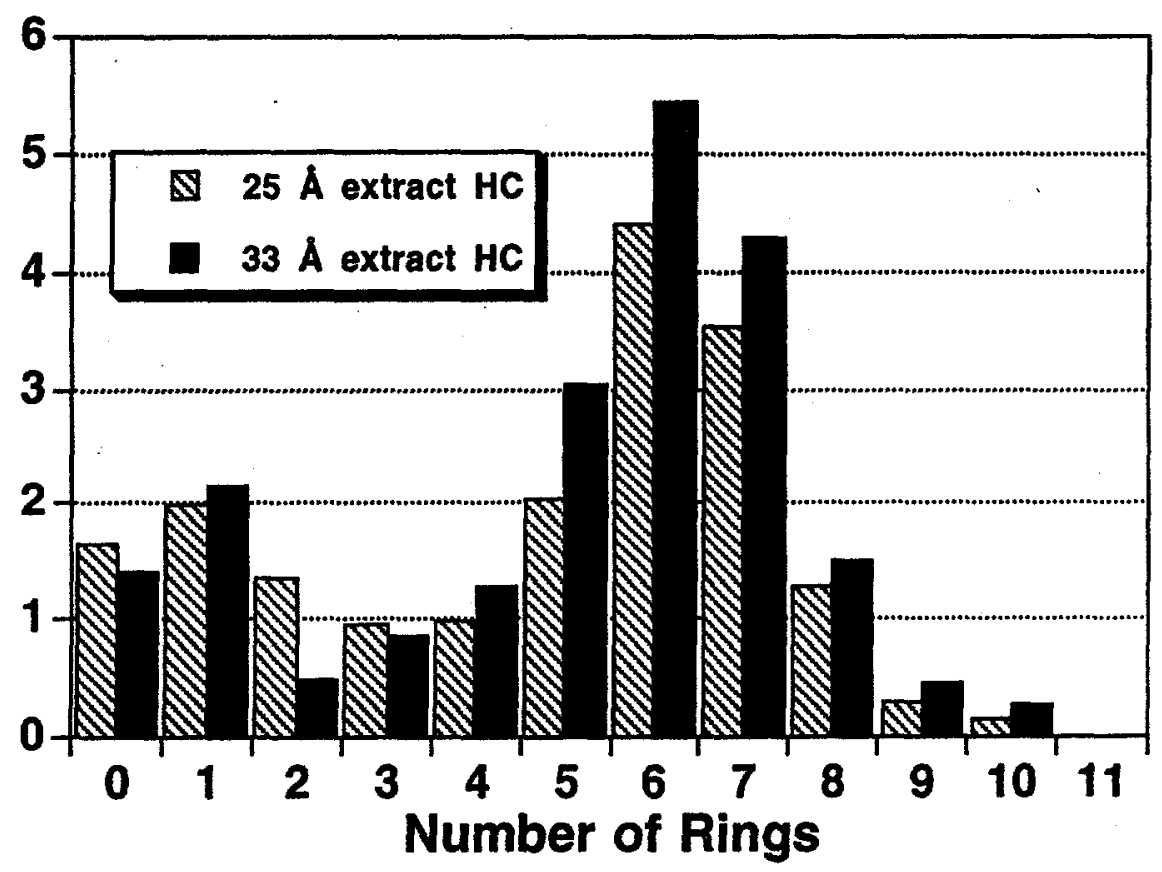

Fig 4. Comparison of aromatic ring size from HRLVMS of methylene chloride extracts of $25 \AA$ and $33 \AA$ M41S sieves loaded with pyridine extracts of Upper Freeport coal (APCS 1).

\section{ACKNOWLEDGMENT}

This work was supported by the Division of Chemical Sciences, Office of Basic Energy Sciences, U. S. Department of Energy, under contract W-31-109-ENG-38.

\section{REFERENCES}

1. Cody, G.D., Thiyagarajan, P., Botto, R. E., Hunt, J. E., Winans, R. E., Energy Fuels, 1994. 8(6): p. 1370-8.

2. Beck, J. S., U.S. Pat., No. 5,057,296, 1991

3. Beck, J. S.; Vartuli, J. C.; Roth, W. J.; Leonowicz, M. E.; Kresge, C. T.; Schmitt, K. D.; Chu, C. TW.; Olson, D. H.; Sheppard, E. W.; McCullen, J. B.; Higgins, J. B.; Schlenker, J. L., J. Am. Chem. Soc., 1992, 114, 10834-43

4. Vorres, K., Energy \& Fuels 4, 420-426 (1990)

5. Pinnavaia, T. J.; Thorpe, M. F., Access in Nanoporous Materials, Plenum Press: New York, 1995. 